\title{
Enhanced Peptide Molecular Imaging Using Sodium Salt Aqueous Droplets*
}

\author{
M. Komatsu, ${ }^{\dagger}$ Y. Murayama, K. Kuge, and H. Hashimoto \\ Canon Research Center, Leading-edge Technology Development, \\ Canon Inc., 3-30-2 Shimomaruko, Ohta-ku, Tokyo 146-8501, Japan \\ (Received 15 November 2005; Accepted 15 February 2006; Published 2 May 2006)
}

\begin{abstract}
A new method, droplet-enhanced secondary ion mass spectrometry (SIMS), was developed for the molecular imaging analysis of biological samples. To facilitate the ionization of bio-molecules, a few microliters of aqueous solution containing sodium salt was dropped onto a peptide sample before time of flight (TOF)-SIMS measurement. Using this method, we have successfully obtained strong molecular secondary ion signals from molecular weight $(\mathrm{MW})<1587$ peptide samples while maintaining their natural distribution. On the basis of various experiments, we observed that a neutral sputtered peptide molecule $\left(\mathrm{M}^{0}\right)$ is effectively ionized by collision with a sodium ion $\left(\mathrm{Na}^{+}\right)$ above the sample surface $\left(\mathrm{M}^{0} \leftarrow \mathrm{Na}^{+}\right)$, and excess sodium salt doped onto the sample has effect on inhibition of the positive ion formation. This method enables to simultaneously induce the ionization of each peptide present in a multicomponent solution. We also succeeded in detecting and quantifying nanogram levels of peptides with bubble jet (BJ) printing droplets. The results obtained indicate the usefulness of TOF-SIMS for micro-meter order sized peptide/protein screening system for assessing disease and drug efficacy. [DOI: 10.1380/ejssnt.2006.468]
\end{abstract}

Keywords: Secondary ion mass spectroscopy; Bioimaging and engineering; Biological molecules - proteins; metal cationization; bubble jet printing

\section{INTRODUCTION}

A method for visualizing the distribution of proteins/peptides in biological samples, such as a protein chip or tissue, has become very important. Time of flight secondary ion mass spectrometry (TOF-SIMS) has been applied due to its imaging capability of spatial resolutions approaching the submicron-meter level, whereas Matrixassisted laser desorption ionization mass spectrometry (MALDI-MS) [1, 2] has been widely used. TOF-SIMS generally has a disadvantage, that is, its detection capability is limited in measurement for small peptides with molecular weight ranging in $(\mathrm{MW})<1000$. Consequently, conventional TOF-SIMS technique is insufficient for the accurate discrimination of species in typical biological samples, and a method for detecting large peptide molecules is required.

Recently, some methods of enhancing the ionization of molecular ions have been reported on the mapping distribution of peptide samples by TOF-SIMS. The so-called Matrix-enhanced SIMS (ME-SIMS) [3] is a representative method, in which the sample is prepared by the same method as that in MALDI-MS. ME-SIMS makes it possible to generate the molecular ions from a range of proteins and polypeptides with MW $<10000$. However, it is extremely difficult to obtain information on the natural distribution of the each species in a sample without their migration. Thus, we have investigated a new method, droplet- enhanced secondary ion mass spectrometry. In this method, a small amount of aqueous solution containing an enhancing agent is dropped using pipettes or bubble jet (BJ) printing $[4,5]$ method onto peptide samples with maintaining the natural distribution of each species

*This paper was presented at 5th International Symposium on Atomic Level Characterizations for New Materials and Devices (ALC05), Hawaii, USA, 4-9 December, 2005.

$\dagger$ Corresponding author: komatsu.manabu@canon.co.jp before TOF-SIMS measurement.

Peptide molecules are generally detected as protonated molecular ions and its yield is enhanced using acids $[6,7]$. Appling this method, we also succeeded in the observation of strong molecular secondary ion signals of peptide samples in the range of $2531<\mathrm{MW}<7649$ by use of peptide samples using trifluoroacetic acid (TFA) as an enhancing agent [8]. However this enhancing method was not effective for peptide molecular size ranging in about $\mathrm{MW}<2000$. Herein, we report on secondary ion enhancement by addition of aqueous droplets containing a sodium salt to peptides ranging in $\mathrm{MW}<1587$. This sodium salt ionization-enhancement technique is well known as a metal-cationization process [9] by which a neutral molecule (M) captures a metal atom (Me) to form a metal adduct ion $\left([\mathrm{M}+\mathrm{Me}]^{+}\right)$, but the detailed mechanism is not completely understood. For improvement of the ionization efficiency and acquisition of higher molecular weight ions, we have studied the mechanism of the sodium-cationization. Moreover, applying BJ printing to drop a very small amount of sodium salt solution, we succeeded in improving the precision of sample preparation.

\section{EXPERIMENTAL}

\section{A. Sample preparation}

Each peptide was dissolved in deionized water to a concentration of $5 \times 10^{-4} \mathrm{M}$. Droplet $(1.5 \mu \mathrm{l})$ of each peptide solution was typically spread out onto gold deposited on a silicon wafer ( $\mathrm{Au} / \mathrm{Si}$ substrate) and dried in air at room temperature. Then, $1.0 \mu \mathrm{l}$ of aqueous solution containing a sodium salt agent such as $\mathrm{Na}_{2} \mathrm{CO}_{3}$ was dropped onto peptide films before TOF-SIMS measurement.

BJ dot spotted sample was prepared using a modified BJ printer (PIXUS 990i, Canon Inc.). The printer head was mounted on a printing device, which spotted $4 \mathrm{pl}$ of sodium salt solution $\left(1 \times 10^{-4} \mathrm{M}\right)$ as an ionization- 

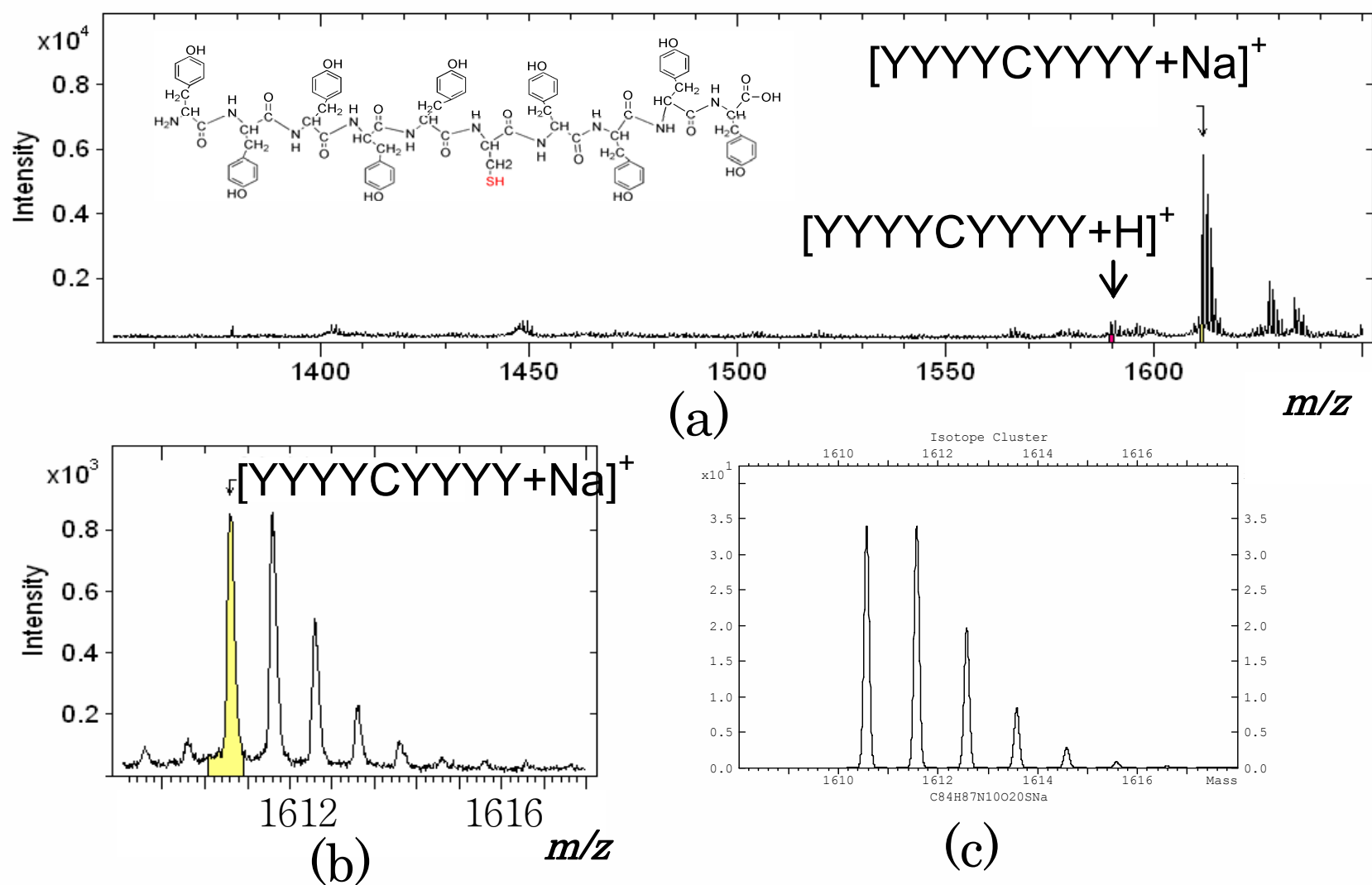

(a)

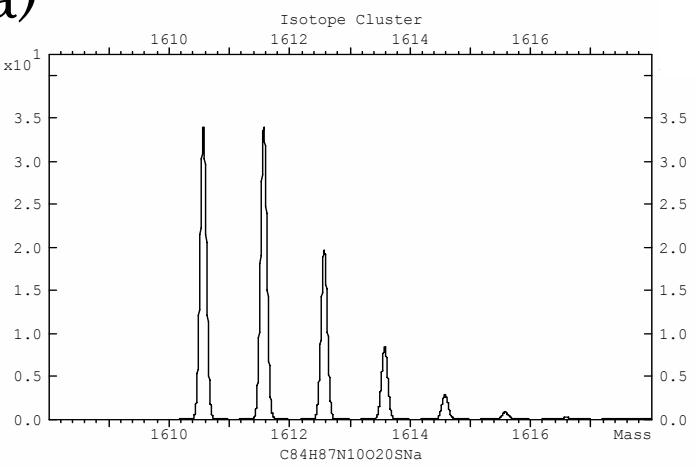

(c)

FIG. 1: Positive ion TOF-SIMS mass spectrum of YYYYCYYYYY (MW 1588) from thin film sample after enhancing treatment by $\mathrm{Na}_{2} \mathrm{CO}_{3}$ aq. Droplet: (a) measured spectrum of wide mass range, the inset shows the peptide molecule structure (b) expansion of (a) in vicinity of $[\mathrm{YYYYCYYYYY+Na}]^{+}$, (c) calculated spectrum of [YYYYCYYYYY $\left.+\mathrm{Na}\right]^{+}$.

enhancing agent onto the $\mathrm{Au} / \mathrm{Si}$ substrate. The spotting was carried out for $10 \mathrm{~mm} \times 10 \mathrm{~mm}$ and a pitch was about $50 \mu \mathrm{m}$.

\section{B. TOF-SIMS measurement}

Positive ion TOF-SIMS spectra and images were obtained on TOF-SIMS IV (ION-TOF GmbH instrument) equipped with a $\mathrm{Ga}^{+}$primary ion gun. The ion gun with a current of $0.7 \mathrm{pA}$ (pulse current) was operated at $25 \mathrm{kV}$ and a pulse width of 0.8 ns. Electron flood gun was not operated. TOF-SIMS spectra and images were obtained over an area of $300 \mu \mathrm{m} \times 300 \mu \mathrm{m}$ in a sawtooth scanning mode while maintaining a primary ion dose below the static SIMS limit of $2 \times 10^{12}$ ions $/ \mathrm{cm}^{2}$.

\section{RESULTS AND DISCUSSION}

\section{A. Metal cationization process in SIMS}

TOF-SIMS spectrum of the synthetic peptide YYYYCYYYYY $\left(\mathrm{C}_{84} \mathrm{H}_{87} \mathrm{~N}_{10} \mathrm{O}_{20} \mathrm{~S}, \quad \mathrm{MW}\right.$ 1587.7) film after $\mathrm{Na}_{2} \mathrm{CO}_{3}$ aqueous droplet $\left(1 \times 10^{-4} \mathrm{M}\right)$ treatment is shown in Fig. 1. Strong signals of the peptide molecular ions added by a sodium atom, [YYYYCYYYYY+Na] ${ }^{+}$ were observed from the sample after the droplet treat- ment. This result suggests the sodium salt has an ion enhancement effect with the cationization of the molecules. Moreover, it is noteworthy that the molecules are cationized without any loss of molecular weight of the peptide. This effect is interpreted from two types of the cationization process during SIMS sputtering. One is a neutral sputtered peptide molecule $\left(\mathrm{M}^{0}\right)$ is ionized by collision with a sodium cation $\left(\mathrm{Na}^{+}\right)$above the sample surface $\left(\mathrm{M}^{0} \leftarrow \mathrm{Na}^{+}\right)$. The other is a peptide molecule captured with chemical addition of a sodium atom has a tendency to induce the adsorption of proton $\left(\mathrm{H}^{+}\right)$above the sample surface (e.g. $[\mathrm{M}-\mathrm{COONa}]^{0} \leftarrow \mathrm{H}^{+}$).

To confirm the effect of metal cationization enhancement of molecular ion signals, we investigated the relation between various types of peptides and metal salts for the agent in the droplet treatment. The results are listed in Table I. $\mathrm{Na}_{2} \mathrm{CO}_{3}$ is the most effective promoter for the ionization of peptide molecules raging in $\mathrm{MW}<1587$. Moreover, we found that the cationization enhancement has dependence on the molecular size. Though attempting with various types of peptide molecules ranging in about MW > 2000, the effect of metal cationization was not observed. Next, representing TOF-SIMS spectra obtained from the metal cationized peptide molecules in the Table I: (I) Morphiceptin (PFPY: $\mathrm{C}_{28} \mathrm{H}_{33} \mathrm{~N}_{4} \mathrm{O}_{6}, \mathrm{MW}$ 521.3) and (II) Methionine enkephalinamide (YGGFM$\mathrm{NH}_{2}: \mathrm{C}_{27} \mathrm{H}_{36} \mathrm{~N}_{6} \mathrm{O}_{6} \mathrm{~S}, \mathrm{MW}$ 572.7) are shown in Figs. 2-I and 2-II, respectively. Comparison of two spectra in Figs. 2 -I and II reveal, that both of the peptide ion intensi- 
(I)

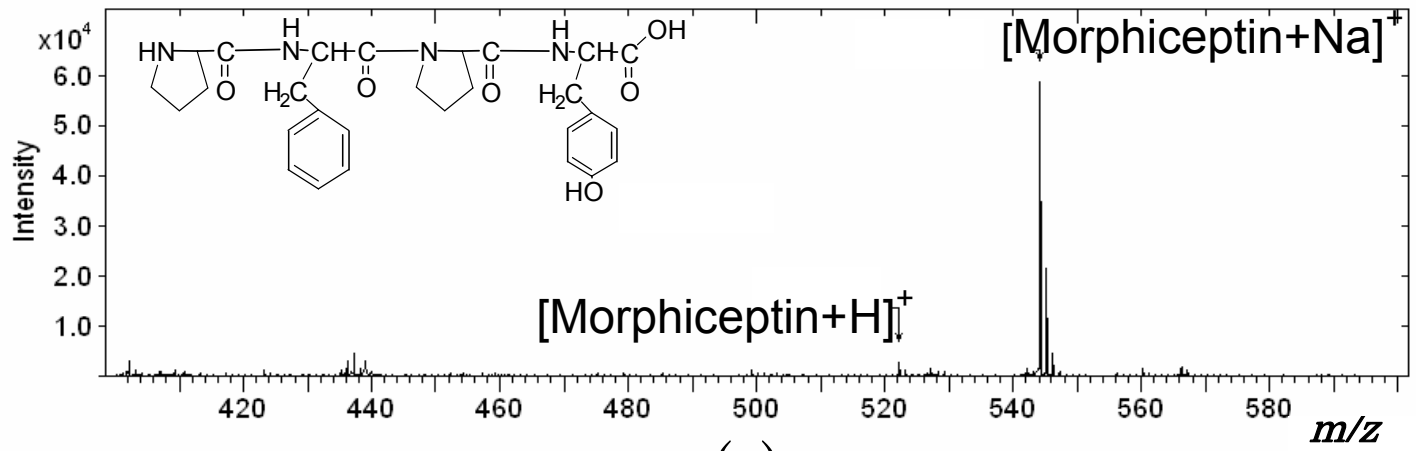

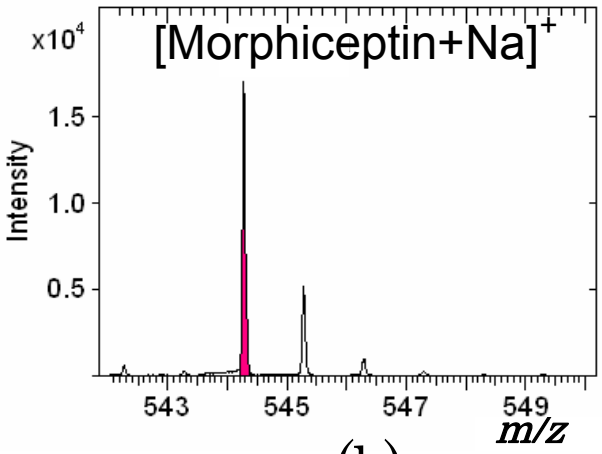

(b)

(a)

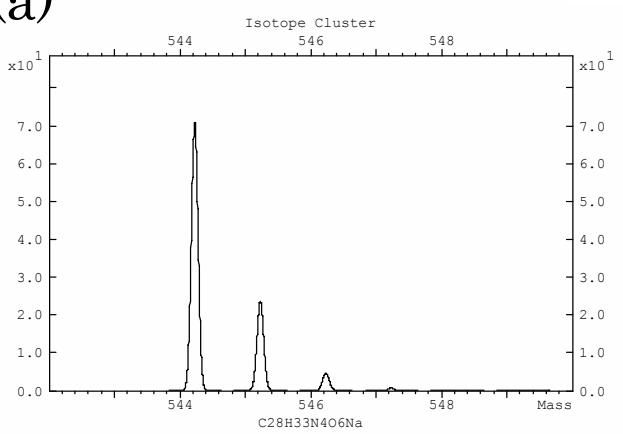

(c)

\section{(II)}

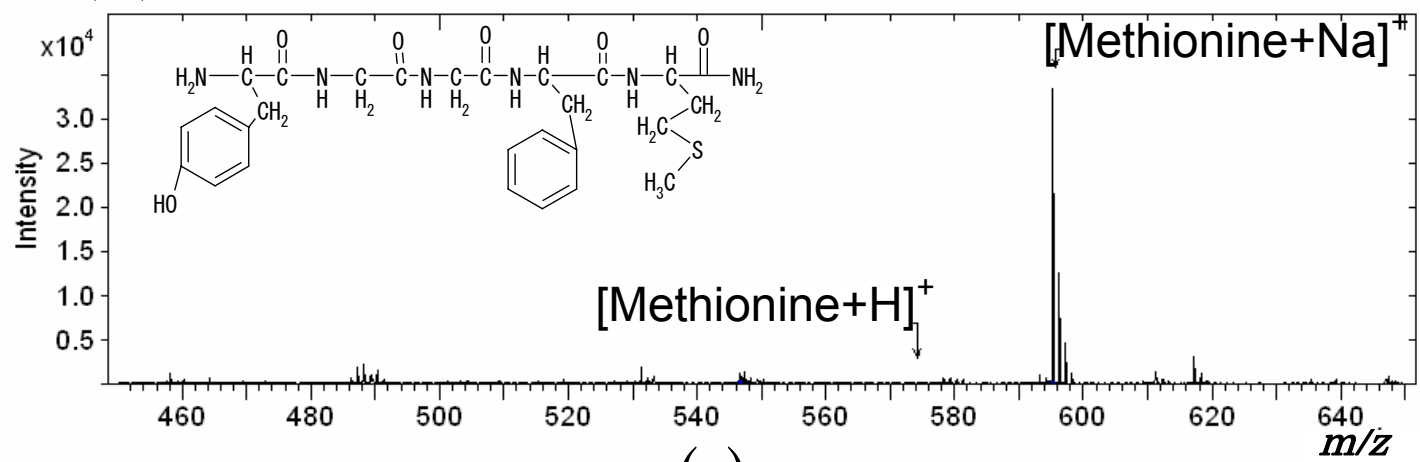

(a)

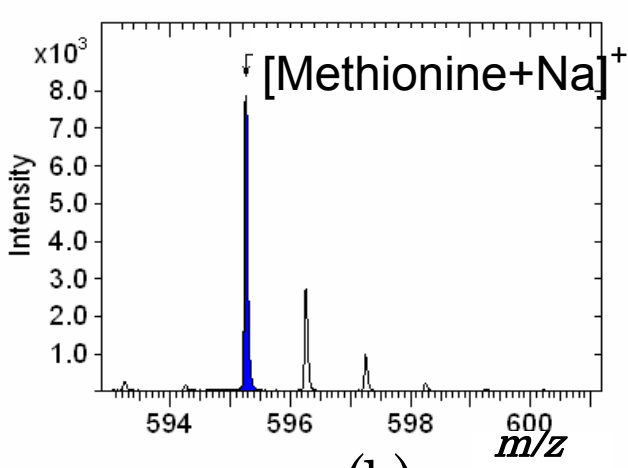

(b)

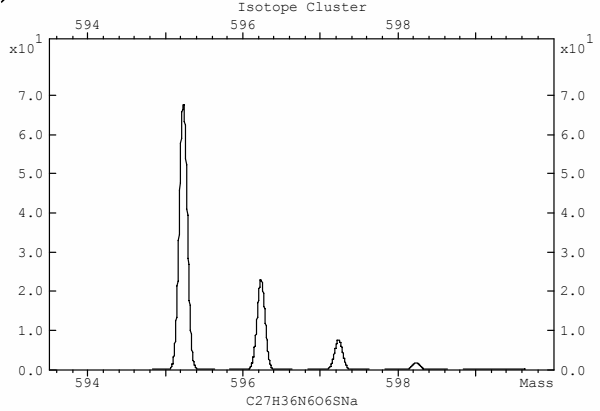

(c)

FIG. 2: Positive ion TOF-SIMS mass spectrum of (I) Morphiceptin (MW 521) and (II) Methionine enkephalinamide (MW 572) from thin film sample after enhancing treatment by $\mathrm{Na}_{2} \mathrm{CO}_{3}$ aq.droplet, respectively: (a) measured spectrum of wide mass range, the inset shows the peptide molecule structure (b) expansion of (a) in vicinity of $[\mathrm{M}+\mathrm{Na}]^{+}$, (c) calculated spectrum of $[\mathrm{M}+\mathrm{Na}]^{+}$.

ties are equally promoted by the sodium cationization. Though Methionine enke- phalinamide has neither car- boxyl group (-COOH) nor mercapto collision of a neutral sputtered peptide molecule and a sodium ion above the 
TABLE I: Attempt to detect many type of peptide by various promoting salt agent for aqueous droplet treatment. S: signal $>10,000$ counts, M: 1,000 < signal $<5,000$ counts, W: signal $<100$ counts, -: no signal.

\begin{tabular}{|c|c|c|c|c|c|c|}
\hline \multirow[b]{2}{*}{ analyte } & \multirow[b]{2}{*}{$(\mathrm{amu})$} & \multirow[b]{2}{*}{ neat } & \multicolumn{4}{|c|}{ Promoting Agent } \\
\hline & & & $\mathrm{Na} 2 \mathrm{CO} 3 \mathrm{aq}$ & $\mathrm{K} 2 \mathrm{CO} 3 \mathrm{aq}$ & AgNO3aq & AgTFAaq \\
\hline Morphiceptin & 521 & M & $\mathrm{S}$ & $\mathrm{S}$ & S & $\mathrm{S}$ \\
\hline Methionine enkephalinamide & 572 & M & $\mathrm{S}$ & $\mathrm{S}$ & $\mathrm{S}$ & $\mathrm{S}$ \\
\hline Syncetic polypeptide & & & & & & \\
\hline GGGGCGGGGG & 635 & $\mathrm{~W}$ & $\mathrm{~S}$ & M & - & - \\
\hline YYYYCYYYYY & 1588 & $\mathrm{~W}$ & $\mathrm{~S}$ & M & - & - \\
\hline
\end{tabular}
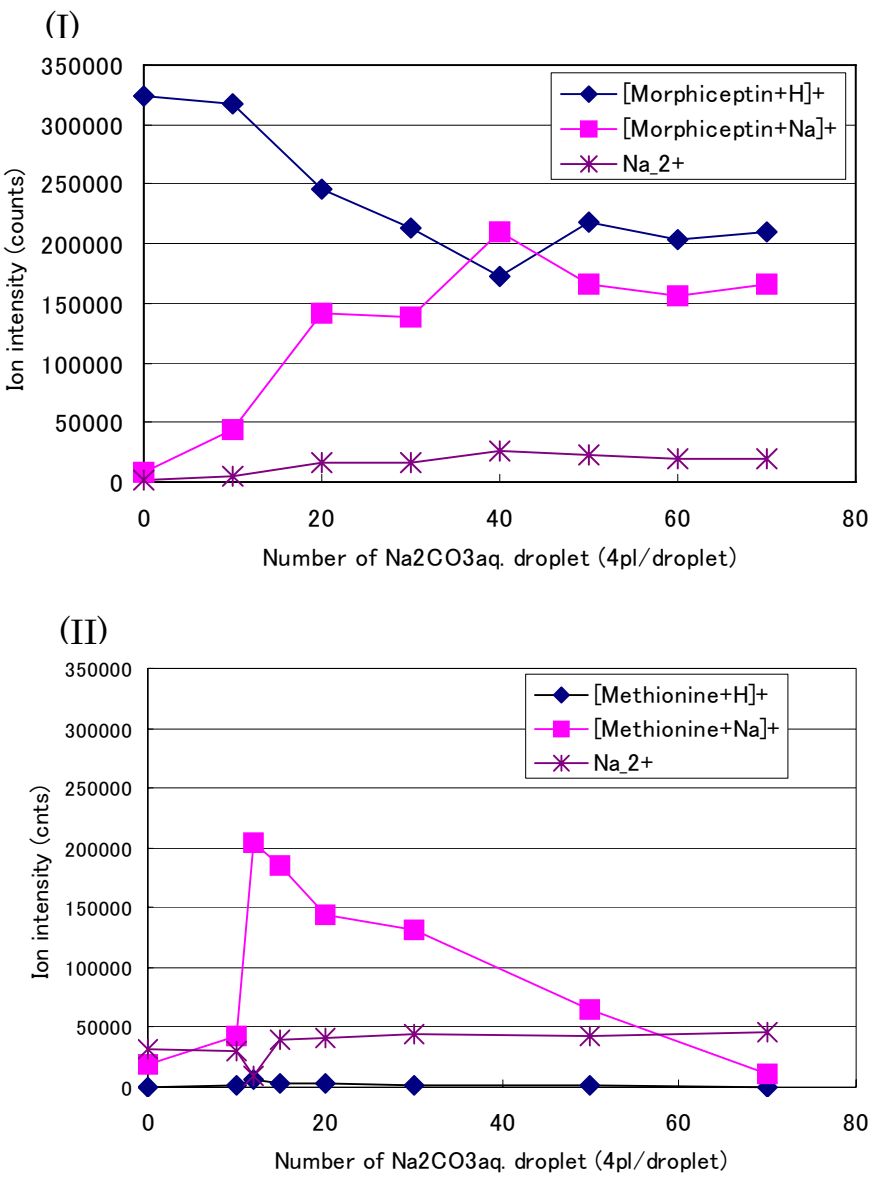

FIG. 3: Relation between the cationized peptides: (I) Morphiceptin, (II) Methionine Enkephalinamide ion intensity and the number of $\mathrm{Na}_{2} \mathrm{CO}_{3}$ aq. BJ droplet.

sample surface. This cationization process is compatible with the fact that the normal peptide molecules are generally detected as protonated molecular ions $\left([\mathrm{M}+\mathrm{H}]^{+}\right)$ formed by the collision of a neutral sputtered peptide molecule and plenty of a proton through SIMS sputtering process $\left(\mathrm{M}^{0} \leftarrow \mathrm{H}^{+}\right)$. Considering both ionization of sodium and hydrogen atoms at the same time in the SIMS process, prior sodium ionization probably occurs due to lower ionization energy of sodium atom $(5.13 \mathrm{eV})$ than that of hydrogen atom $(13.6 \mathrm{eV})$ and frequent charge transfer between them. Thus, sodium cationization with the collision could occur effectively.

\section{B. Quantitative doping by use of BJ printing droplets}

To inspect the appropriate amount of sodium agent for the metal cationization, we attempt to apply BJ printing. First, Morphiceptin and Methionine enkephalinamide films were created using spincoat on $\mathrm{Si}$ wafer, respectively. Then, $4 \mathrm{pl} \mathrm{Na}_{2} \mathrm{CO}_{3}$ aqueous $\left(1 \times 10^{-4}\right.$ $\mathrm{M})$ droplets were dropped in the range from 1 to 70 times onto these peptide films using repetitive BJ printing. The results are shown in Figs. 3-I and II. In case of Morphiceptin (Fig. 3-I), the sodium adducted ion $\left([\text { Morphiceptin }+\mathrm{Na}]^{+}\right)$intensity first gently incre- ased with increasing the number of droplets, whereas the protonated peptide ion $\left([\text { Morphi- ceptin }+\mathrm{H}]^{+}\right)$intensity decreased. Both of the intensities remained then practically constant after repetitive BJ droplet exceeds 40 times. This probably shows that the chemical substitution with $\mathrm{H}$ and $\mathrm{Na}$ on the carboxyl group $(-\mathrm{COOH})$ attained equilibrium. On the other hand, in Fig. 3-II, the sodium adduct ion $\left([\text { Methionin }+\mathrm{Na}]^{+}\right)$intensity shows a rapid rise with increasing the number of droplets reaching a peak at 10 times and the intensity of protonated Methionine ion $\left([\text { Methi- onin }+\mathrm{H}]^{+}\right)$and $\mathrm{Na}^{+}$are weak in constant. We speculate that the origin of this rapid rising is attributable to an untangling of peptide molecules due to sample acidity with increasing of $\mathrm{Na}_{2} \mathrm{CO}_{3}$ doping. Consequently, the increasing of the neutral sputtered peptide molecular ion $\left([\text { Methi- onin }]^{0}\right)$ induces the increasing of $[\text { Methionin }+\mathrm{H}]^{+}$. Further study is necessary to understand the untangling of peptide molecules. The number of BJ droplet exceeding 10 times, the $[\text { Methi- onin }+\mathrm{Na}]^{+}$intensity decreased gradually due to influence of $\mathrm{Na}^{+}$blocking effect induced with exceed sodium doping [10].

\section{Ion images of the multi-component peptides sample}

The TOF-SIMS images of the BJ dot sample are shown in Fig. 4. The images of molecular ions corresponding to each peptide were clearly observed from multi-component peptides sample pre- pared by a multihead BJ printing. The number of peptide molecules in one BJ dot ranges of from about 0.2 to $0.6 \mathrm{fmol}$ and the diameter was about $30 \mu \mathrm{m}$. Therefore, it was demonstrated that the mass images of large peptide molecules with MW $<1587$ could be obtained by TOF-SIMS in extremely high sensitivity and fine region. 


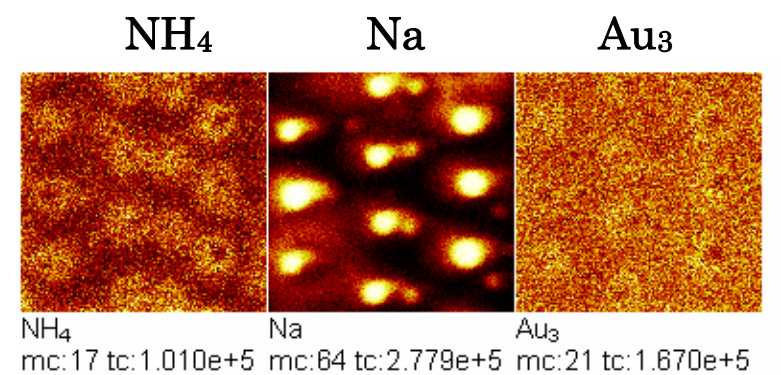

mc: 17 tc: $1.010 \mathrm{e}+5 \mathrm{mc}: 64$ tc: $2.779 \mathrm{e}+5 \mathrm{mc}: 21$ tc: $1.670 \mathrm{e}+5$

$100 \mu \mathrm{m}$

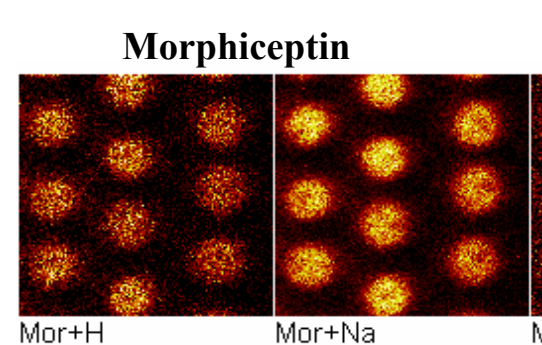

Methionine

Enkephalinamide

YYYYCYYYYY
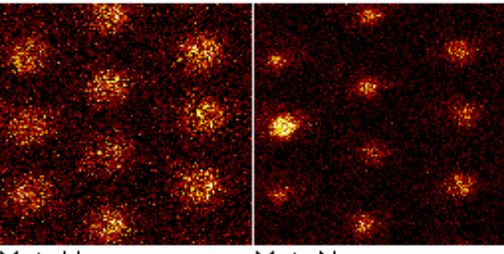

Met $+\mathrm{Na}$

(c)

(d)

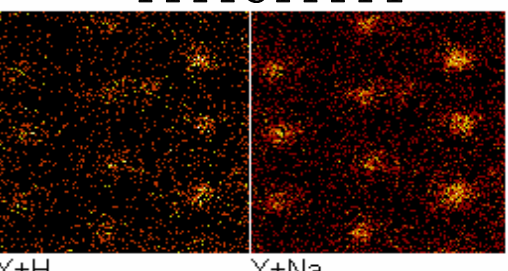

$\mathrm{Y}+\mathrm{Na}$

(a)

(b)

(e)

(f)

FIG. 4: TOF-SIMS imaging from Multicomponent peptide sampling dot by a multihead BJ printing: (a) $[\text { Morphiceptin }+\mathrm{H}]^{+},(\mathrm{b})[\text { Morphiceptin }+\mathrm{Na}]^{+},(\mathrm{c})[\text { Methionine enkephalinamide }+\mathrm{H}]^{+},(\mathrm{d})[\text { Methionine enkephalinamide }+\mathrm{Na}]^{+}$, (e) $[\mathrm{YYYYCYYYYY+H}]^{+}$, (f) $[\mathrm{YYYYCYYYYY+Na}]^{+}$.

\section{CONCLUSIONS}

We investigated a new method, the droplet- enhancement with metal cationization, to visualize the distribution of biomaterials by TOF-SIMS, and determined the effective agent for enhancing the ionization of large peptide molecules with $\mathrm{MW}<1587$. In addition, we attempted to obtain the mass images of these large peptide molecules by BJ printing. The main results of this study are as follows:

( 1 ) Sodium salt is a very effective agent for enhancing the ionization of large peptides and its addition to the sample enabled to detect peptides with MW $<1587$.
( 2 ) The sodium cationization in SIMS is caused by the collision of sputtered neutral peptide molecular and sodium ion in the mixing area, working effectively under a condition of a proper sodium doping.

( 3 ) It is possible to visualize the BJ printing dot of the synthetic peptide (MW 1587) by the dropletenhancement with sodium cationization. Therefore, mapping of the small amount of large peptide molecules (sub-femtmolar order) in a fine region (some $10 \mu \mathrm{m} \phi$ ) becomes feasible by combination of TOF-SIMS and BJ printing technique.
[1] S. L. McArthur, M. C. Vendettuoli, B. D. Ratner, D. G. Castner, Langmuir 20, 3704 (2004).

[2] M. Karas, U. Bahr, U. Giebmann, Mass Spectrom. Rev. 10, 335 (1991).

[3] K. J. Wu, R. W. Odom, Anal. Chem. 68, 873 (1996).

[4] T. Hara, I. Endo, J. Inst. Image Electron. Eng. Jpn. 11, 66 (1982).

[5] A. Asai, S. Hirasawa, I. Endo, J. Imaging Tech. 14, 120 (1988).

[6] A. Benninghoven, W. K. Sichtermann, Anal. Chem. 50,
1180 (1978).

[7] K. L. Busch, S. E. Unger, A. Vincze, R. G. Cooks, T. Keough, J. Am. Chem. Soc. 104, 1507 (1982).

[8] Y. Murayama, M. Komatsu, K. Kuge, H. Hashimoto, Appl. Surf. Sci. (accepted for publication)

[9] A.Delcorte, N.Medard, P. Bertrand, Anal. Chem. 74, 4955 (2002).

[10] C. Dall' Asta, S. Sforza, G. Galaverna, A. Dossena, R. Marchelli, J. Cromatography A 1054, 389 (2004). 